\title{
Highly varying daytime sodium airglow emissions over an equatorial station: a case study based on the measurements using a grating monochromator
}

\author{
Md Mosarraf Hossain*, Chandrashekheran Nair Vineeth, Sukumaran Nair Geetha Kumari Sumod \\ and Tarun Kumar Pant
}

\begin{abstract}
A case study is performed to investigate the probable reasons behind substantial daytime sodium ( $\mathrm{Na}$ ) $\mathrm{D}_{1}$ airglow intensity $(589.6 \mathrm{~nm})$ variations measured using a ground-based monochromator during the three near consecutive days of February 2007 from Trivandrum $\left(8.5^{\circ} \mathrm{N}, 77^{\circ} \mathrm{E}\right)$, India. The roles of both the resonance fluorescence and the chemistry have been considered in this study. It appears that fluorescence plays only a minor role towards the observed five to nine times of large intensity variations among these days. From investigations on the role of chemistry, it seems that through the Chapman chemical scheme, $\mathrm{Na}$ abundance contribute favorably, while the $\mathrm{O}_{3}$ concentrations and the ambient temperature do not play any role as such for the observed intensity variations. From further investigations, it transpires that because of pressure differences (approximately 0.0002 to $0.0003 \mathrm{hPa} / \mathrm{day}$ ) in the emitting altitude region among these days, the variations in collisional quenching of excited $\mathrm{NaO}^{*}\left(\mathrm{~A}^{2} \Sigma^{+}\right)$(first excited electronic state of $\mathrm{NaO}$ that produces $\mathrm{D}$ line) contribute considerably towards the observed intensity variations. From consideration of all the possible factors, it appears that whereas resonance fluorescence plays only a minor role, chemistry has contributed to greater extent towards the observed significant intensity differences among these days.
\end{abstract}

Keywords: Daytime sodium airglow; Resonance fluorescence; Collisional quenching; Mesospheric chemistry

\section{Background}

The atmospheric sodium $(\mathrm{Na})$ layer was discovered in 1929 by Vesto Melvin Slipher, when radiation at $589 \mathrm{~nm}$ was observed in the night sky spectrum (Slipher 1929), and later identified as airglow emitted by neutral sodium atoms within the atmosphere (Bernard 1939). It is now well established that the major source of $\mathrm{Na}$ in the mesosphere lower thermosphere (MLT) region is the sporadic ablation of the meteorites entering the Earth atmosphere. The neutral/ionic forms of sodium constitute the mesospheric sodium layer that typically extends from 80 to $110 \mathrm{~km}$ in altitude and peaks in concentration at around $90 \mathrm{~km}$. Since the discovery of $\mathrm{Na}$ layer in the late 1930s, several investigators have studied the origin and variation of this layer and the $\mathrm{Na}$ airglow originated therein

\footnotetext{
* Correspondence: mosarraf_sw@yahoo.co.in

Space Physics Laboratory, Vikram Sarabhai Space Centre, Trivandrum 695022,
} India

(Blamont and Donahue 1961; Gibson and Sandford 1972; Kirchhoff and Clemesha 1983; Zahn et al. 1988; Clemesha et al. 1995; She et al. 2000; Fan et al. 2007; Kumar 2007; Sarkhel et al. 2009). However, all these investigations were confined to either the night-time or satellite-based daytime studies. Since daytime groundbased measurements of sodium airglow are particularly difficult to perform, there were no contemporary systematic studies so far. Only recently, a ground-based high-resolution monochromator (with maximum resolution of $0.05 \AA$ using $2,400 \mathrm{~g} / \mathrm{mm}$ grating) has been used for systematic measurement of the daytime sodium $D_{1}$ airglow (589.6 nm) (Hossain et al. 2010).

It is well-known that resonant fluorescence plays a dominant role for the production of daytime $\mathrm{Na}$ airglow. However, photochemical excitations also influence its generation and temporal evolution (Hossain et al. 2010). The 
well-known chemical scheme responsible for excitations of neutral $\mathrm{Na}$ atoms is as follows (Chapman 1939):

$$
\begin{gathered}
\mathrm{Na}+\mathrm{O}_{3} \stackrel{k_{1}}{\longrightarrow} \mathrm{NaO}+\mathrm{O}_{2} \\
\mathrm{NaO}+\mathrm{O} \stackrel{\alpha k_{2}}{\longrightarrow} \mathrm{Na}^{*}\left({ }^{2} \mathrm{P}_{\mathrm{J}}\right)+\mathrm{O}_{2} \\
\stackrel{(1-\alpha) k_{2}}{\longrightarrow} \mathrm{Na}\left({ }^{2} \mathrm{~S}\right)+\mathrm{O}_{2} \\
\mathrm{Na}^{*}\left({ }^{2} \mathrm{P}_{\mathrm{J}}\right) \stackrel{\mathrm{Na}\left({ }^{2} \mathrm{~S}\right)+\mathrm{h} v(589,589.6 \mathrm{~nm})}{\longrightarrow}
\end{gathered}
$$

where ' $k_{1}$,' ' $k_{2}$ ' are the respective rate coefficients and ' $\alpha$ ' is the branching ratio for reaction (2), which actually determines the fraction of the $\mathrm{Na}$ atoms that produces $\mathrm{Na}$ airglow. The abundance of $\mathrm{O}_{3}$ relevant to reaction (1) is controlled by the following reaction:

$$
\mathrm{O}+\mathrm{O}_{2}(+\mathrm{M}) \longrightarrow \mathrm{O}_{3}(+\mathrm{M})
$$

where ' $M$ ' denotes a third body, usually $\mathrm{N}_{2}$ molecule or $\mathrm{O}$ atom. Temperature-dependent reaction rate coefficient $k_{1}$ of Equation 1 is given by

$$
k_{1}=1.1 \times 10^{-9} \exp (-116 / T) \mathrm{cm}^{3} / \mathrm{s}
$$

where ' $T$ ' is the absolute temperature in the concerned atmospheric height. It is known that the reaction of Equation 1 is rate determining because above $84 \mathrm{~km}$, $\left[\mathrm{O}_{3}\right]$ « $[\mathrm{O}]$ (Plane 2003), where the square bracket denotes the concentration of the concerned species. Hence, the volume emission rate (VER) of the $\mathrm{Na} \mathrm{D}$ emissions can be expressed by

$$
R_{\mathrm{Na}}=\alpha k_{1}[\mathrm{Na}]\left[\mathrm{O}_{3}\right]
$$

Equation 6 includes contributions from both the $D_{1}$ and $\mathrm{D}_{2}$ lines of $\mathrm{Na}$. The present investigation involves measurement of only the $\mathrm{D}_{1}$ line intensity, and hence the relevant VER is expressed by

$$
R_{\mathrm{NaD} 1}=\left(1+R_{\mathrm{D}}\right)^{-1} \alpha k_{1}[\mathrm{Na}]\left[\mathrm{O}_{3}\right]
$$

where, ' $R_{\mathrm{D}}{ }^{\prime}\left(=\mathrm{I}_{\mathrm{D} 2} / I_{\mathrm{D} 1}\right)$ is the ratio of $\mathrm{D}_{2}$ to $\mathrm{D}_{1}$ line intensity. It is evident from the expression (7) that VER is dependent on the parameters $k_{1}, \alpha$, and $R_{\mathrm{D}}$ in addition to the prevailing $[\mathrm{Na}],\left[\mathrm{O}_{3}\right]$.

The role of the Chapman chemical scheme in producing the $\mathrm{Na}$ airglow at the MLT region has been recognized over the years. Plane (2003) had presented a review on the validity of this scheme. However, in the context of explaining the observed $\mathrm{Na}$ airglow intensity and its variation, there has been widespread debate over the values of $\alpha$ and $R_{\mathrm{D}}$. Clemesha et al. had estimated the value of $\alpha$ to be within 0.05 to 0.2 with a best estimate of 0.1 based on the rocket-borne photometry and ground-based lidar measurements (Clemesha et al. 1995). Also, Hecht et al. had found the value of $\alpha$ in between 0.02 and 0.04, even though temperature of the mesopause region on that night was very low $(165 \mathrm{~K})$ and the Na layer and the airglow emission layers were peaked around $95 \mathrm{~km}$ (Hecht et al. 2000). In contrast to these evaluations, considerably smaller value (less than 0.01 ) of $\alpha$ was found in an early laboratory measurement (Plane and Husain 1986). The reasons for these disagreement in the values of $\alpha$ have been looked at through a series of laboratory experiments, and it has been found that the earlier laboratory estimate of Plane and Husain was smaller, probably because reaction (1) produces most of the $\mathrm{NaO}$ in the $\left(\mathrm{A}^{2} \Sigma^{+}\right)$excited electronic state rather than in the $\left(\mathrm{X}^{2} \Pi\right)$ ground state (Shi et al. 1993; Wright et al. 1993), and excited $\mathrm{NaO}^{\prime \prime}\left(\mathrm{A}^{2} \Sigma^{+}\right)$ (") denoting excited state) has a longer radiative lifetime and is not quenched effectively by $\mathrm{N}_{2}$. Hence, reaction (2) should involve mainly the $\mathrm{NaO}^{\prime \prime}$ (A) (Joo et al. 1999). Also, in 2001, through an elegant experiment, Griffin et al. had shown that $\alpha$ for $\mathrm{NaO}^{*}(\mathrm{~A})+\mathrm{O}$ is $0.14 \pm 0.04$ (Griffin et al. 2001). This indicates that the earlier laboratory estimate of $\alpha$ by Plane and Husain was smaller because it involved the reaction between ground-state $\mathrm{NaO}(\mathrm{X})$ and $\mathrm{O}$. Hence, the inconsistency in the values of $\alpha$ is not explainable with the original Chapman mechanism of reactions (1 to 2).

Also, there have been several recent important studies on the measurement of $\mathrm{D}$ line ratio $R_{\mathrm{D}}$ and its variability. It can be noted that if the excited states ${ }^{2} \mathrm{P}_{J}$ in reaction (2) are populated according to the statistical weights of their spin-orbit coupling, then value of $R_{\mathrm{D}}$ will be 2 . However, there is no a priori reason for the spin-orbit states to be populated statistically. Yet, a D line ratio of $1.98 \pm 0.1$ using a Fabry-Perot interferometer was reported long back (Sipler and Biondi 1978). Surprisingly, in the recent past, it has been seen that the ratio is rather variable (Slanger et al. 2005; Plane et al. 2007; Harrell et al. 2010; Plane et al. 2012). High-resolution airglow spectra were obtained using the High-Resolution Echelle Spectrometer (HIRES) and the Echellette Spectrograph Imager (ESI). Echelle spectrographs coupled to the Keck telescopes in Hawaii showed the value of $R_{\mathrm{D}}$ in between 1.3 and 1.9 (Slanger et al. 2005). There are also some indications of a seasonal dependence, with equinoxes having higher values. An airborne spectrometer flying between $40^{\circ} \mathrm{N}$ and $50^{\circ} \mathrm{N}$ measured the values of $R_{\mathrm{D}}$ varying between 1.4 and 2.0 (average 1.8) and changing over horizontal distances of 50 to $100 \mathrm{~km}$ (Slanger et al. 2005; Plane et al. 2007). The reason for the inconsistency in the recent values of $R_{\mathrm{D}}$ with that of the previous results is still unknown and could not be explained with the original Chapman mechanism. To determine the reason for this discrepancy, laboratory experiments were performed, and the obtained results suggested the dependence of $R_{\mathrm{D}}$ on the ratio of concentrations of atomic to molecular oxygen $([\mathrm{O}] /[\mathrm{O} 2]$ ) (Slanger et al. 
2005). This led Slanger et al. to modify the Chapman mechanism as follows:

$$
\begin{aligned}
& \mathrm{Na}+\mathrm{O}_{3} \longrightarrow \mathrm{NaO}^{*}\left(\mathrm{~A}^{2} \Sigma^{+}\right)+\mathrm{O}_{2}, \\
& \mathrm{NaO}^{*}\left(\mathrm{~A}^{2} \Sigma^{+}\right)+\mathrm{O}\left({ }^{3} \mathrm{P}\right) \longrightarrow \mathrm{Na}^{*}\left({ }^{2} \mathrm{P}_{\mathrm{J}}\right)+\mathrm{O}_{2}, \\
& \mathrm{NaO}^{*}\left(\mathrm{~A}^{2} \Sigma^{+}\right)+\mathrm{M} \longrightarrow \mathrm{NaO}\left(\mathrm{X}^{2} \Pi\right)+\mathrm{M}, \\
& \mathrm{NaO}\left(\mathrm{X}^{2} \Pi\right)+\mathrm{O}\left({ }^{3} \mathrm{P}\right) \longrightarrow \mathrm{Na}^{*}\left({ }^{2} \mathrm{P}_{J}\right)+\mathrm{O}_{2}
\end{aligned}
$$

where, $\mathrm{M}$ represents primarily the ambient $\mathrm{N}_{2}$ and $\mathrm{O}_{2}$ molecules. The modified Chapman scheme of reactions (8 to 11 ) assumes that $\mathrm{NaO}$ is mostly produced in the excited state $\mathrm{NaO}^{\prime \prime}(\mathrm{A})$ rather than in ground-state $\mathrm{NaO}$ (X) following Shi et al. (1993) and Wright et al. (1993). In the modified scheme of reactions (8 to 11), the first possibility is that the excited $\mathrm{NaO}^{\prime \prime}(\mathrm{A})$ produced can be reduced by atomic oxygen to yield the excited $\mathrm{Na}$ atoms, which in turn, de-excites to give the airglow emissions. Secondly, $\mathrm{NaO}^{\prime \prime}$ (A) may be converted to $\mathrm{NaO}$ (X) through collisional quenching with $\mathrm{M}$ before being reacted with $\mathrm{O}$. In a recent paper, Plane et al. (2012) have used a zenithsky viewing telescope and a Czerny-Turner spectrograph for a series of ground-based long-term measurements of $R_{\mathrm{D}}$ at several locations and found that $R_{\mathrm{D}}$ varies between 1.5 and 2.0, with an average value of 1.67 . These results were interpreted using a statistical model of the Na nightglow which involves initial production of electronically excited $\mathrm{NaO}^{\prime \prime}(\mathrm{A})$ from the reaction between $\mathrm{Na}$ and $\mathrm{O}_{3}$, followed either by reaction with $\mathrm{O}$ to generate $\mathrm{Na}\left({ }^{2} \mathrm{P}_{J}\right)$ with a branching ratio $\alpha$ of $1 / 6$ and a $J=3 / 2$ to $1 / 2$ spinorbit propensity of 2.0 or quenching of $\mathrm{NaO}^{\prime \prime}(\mathrm{A})$ to $\mathrm{NaO}$ $(\mathrm{X})$ by $\mathrm{O}_{2}$. The resulting $\mathrm{NaO}(\mathrm{X})$ then reacts with $\mathrm{O}$ to generate $\mathrm{Na}\left({ }^{2} \mathrm{P}_{J}\right)$ with a branching ratio of $1 / 6$ and a $J=3 / 2$ to $1 / 2$ spin-orbit propensity of 1.5 (Plane et al. 2012). In the modified Chapman scheme, variations in the values of $\alpha$ and $R_{\mathrm{D}}$ are suggested to depend on whether $\mathrm{NaO}^{*}(\mathrm{~A})$ or $\mathrm{NaO}(\mathrm{X})$ are primarily available in the concerned altitude region. The value of $\alpha$ is on the higher side when $\mathrm{NaO}^{\prime \prime}(\mathrm{A})$ directly reacts with O (Herschbach et al. 1992; Griffin et al. 2001). But, if $\mathrm{NaO}^{*}(\mathrm{~A})$ is quenched by $\mathrm{M}$ [following reaction (10)] to produce $\mathrm{NaO}(\mathrm{X})$ before its reactions with $\mathrm{O}$, the value of $\alpha$ becomes less (Herschbach et al. 1992; Joo et al. 1999). Furthermore, it has been shown by Slanger et al. $(2005,2006)$ that quenching of $\mathrm{NaO}^{\prime \prime}(\mathrm{A})$ to $\mathrm{NaO}(\mathrm{X})$ also affects the value of $R_{\mathrm{D}}$. The reactions (9) and (11) are likely to produce $\mathrm{Na}\left({ }^{2} \mathrm{P}_{1 / 2}\right)$ and $\mathrm{Na}\left({ }^{2} \mathrm{P}_{3 / 2}\right)$ in different proportions depending on the extent of quenching of $\mathrm{NaO}^{\prime \prime}(\mathrm{A})$ with the ambient gas, hence leading to the variations in $R_{\mathrm{D}}$. Hence, it is evident that the ambient collisional quenching plays important role in deciding the variations in $\alpha$ and $R_{\mathrm{D}}$.
As the supporting evidence for the mechanism proposed by Slanger et al. (2005) owing to the possible effects of collisional quenching on $R_{\mathrm{D}}$, a recent paper by Sarkhel et al. (2009) have suggested that the quenching process due to the ambient gas affects the variations in branching ratio $\alpha$ and $R_{\mathrm{D}}$ leading to the observed differences in the $\mathrm{Na}$ airglow. Also, in an another related work to study the influence of altitude-dependent collisional quenching on the observed $\mathrm{Na}$ airglow intensity variation, Sarkhel et al. (2009) has shown that the $\mathrm{Na}$ atom concentration and the $\mathrm{Na}$ airglow intensity are well correlated at a particular altitude that is about one scale height higher than the altitude of maximum $\mathrm{Na}$ concentration. They also have found through the Na airglow VER estimation using the contribution from the mesospheric ozone and temperature data that the peak emission altitude does not match the altitude of the maximum correlation between the $\mathrm{Na}$ atoms and the $\mathrm{Na}$ airglow, and hence suggested that the altitude variation of the pressure-dependent collisional quenching needs to be considered, on this occasion, to account for the observed $\mathrm{Na}$ airglow intensity variation. In a recent paper, Hossain et al. (2010) has reported that daytime $\mathrm{Na}$ airglow exhibits significant variability within a day and from one day to another. Also, it has been shown that the dynamics and the chemistry affect its temporal variation. However, in that study, the roles of the possible factors in controlling the $\mathrm{Na}$ airglow emission rate and its highly varying behavior have not been looked into. In this work, we present the highly varying nature of the daytime $\mathrm{Na}$ airglow intensities measured using a ground-based highresolution monochromator during the three near consecutive days, i.e., 9, 13, and 15 February 2007 on a case study basis. Here, we have considered the roles of the resonance fluorescence through $\mathrm{Na}$ atom concentration and solar radiation, and the chemistry, in terms of the concerned ambient species, and the relevant parameters including $\alpha$ and $R_{\mathrm{D}}$ for the qualitative estimation of VER of $\mathrm{Na}$ airglow to find out the possible reasons behind considerable intensity variations among these days. Variations of $\alpha$ and $R_{\mathrm{D}}$ has been considered in line with the suggestion given by Sarkhel et al. (2009). From the detailed analysis, it appears that whereas resonance fluorescence plays only a minor role, it is the chemistry that plays larger role in controlling the intensity variations among the mentioned days. This work discusses these aspects in detail.

\section{Methods}

\section{Instruments and data used}

A 1-m scanning high-resolution monochromator (GCA McPherson Instrument, Model 2051) in Czerny-Turner configuration has been used for the measurement of daytime $\mathrm{Na}$ airglow from Trivandrum $\left(8.5^{\circ} \mathrm{N}, 77^{\circ} \mathrm{E}\right)$. Schematic of the optical layout of this monochromator is shown in Figure 1. The monochromator uses a 'Snap-In' 


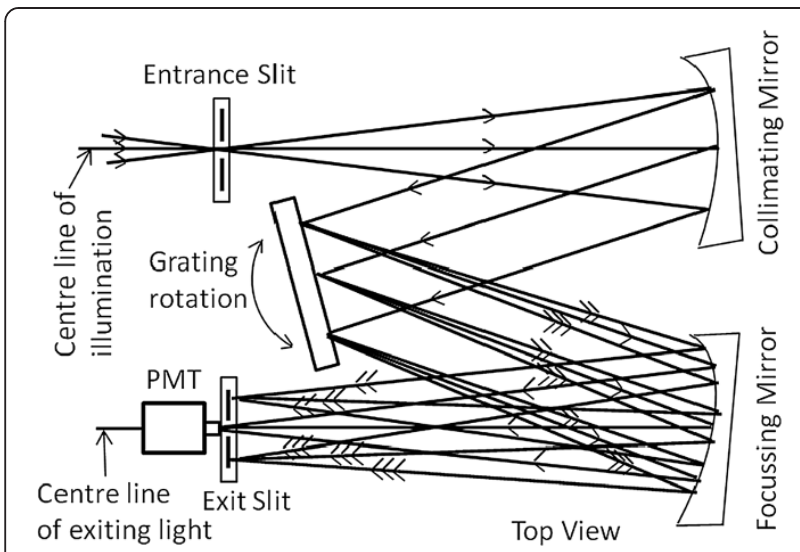

Figure 1 Schematic of the optical layout of the monochromator.

plane ruled grating $(2,400 \mathrm{~g} / \mathrm{mm}$, ruled area $102 \times$ $102 \mathrm{~mm}^{2}$ ) with maximum diffraction efficiency $70 \%$. The system can achieve a maximum resolution of $0.05 \AA$ with this grating. This system employs an image transfer system, which comprises aspheric collimating and focusing mirrors and axial entrance/exit slits. As the detector, a photomultiplier tube (PMT) with multi-alkali cathode is used in the photon counting mode. Signal-to-noise ratio ( $\mathrm{S} / \mathrm{N}$ ratio) of the monochromator does not vary with slit width as light source is continuum, but $\mathrm{S} / \mathrm{N}$ ratio varies inversely with slit height. Hence, in the present case of 50$\mu \mathrm{m}$ slit width and 4-mm slit height, the $\mathrm{S} / \mathrm{N}$ ratio depends mainly on the thermal noise of the detector, which was observed to be approximately 10 to 12 photon counts/20 s of integration time with the PMT cooled to about $-18^{\circ} \mathrm{C}$. The typical count range for $\mathrm{Na}-\mathrm{D}_{1}$ airglow emission was found to be within $4 \times 10^{5}$ to $4 \times 10^{6}$ photon counts $/ 20 \mathrm{~s}$. The monochromator has been augmented with a reflecting optics to direct the light properly through the entrance slit. The reflecting optics consists of a scanning mirror kept on top of the roof, a baffle, and a lightproof box containing a mirror at an angle of $45^{\circ}$. Daylight from the zenith is guided through the reflecting optics of the system to properly fill the acceptance cone of the monochromator, which has an effective aperture of F/8.7. The solar Fraunhoffer D lines separated by approximately $6 \AA$ at wavelengths of 5,890 and 5,896 $\AA$ are located and measured. $D_{1}$ line $(5,896 \AA)$ is chosen for the present study. Near the bottom of this absorption line, $\mathrm{Na}$ emission feature is noticed (Hossain et al. 2010). The system is then tuned to the wavelength position of this emission feature, and the temporal variation of $\mathrm{Na}$ airglow intensity is measured during daytime.

Along with the monochromator, data from a collocated all sky interferometric meteor (SKiYMET) radar (Mardoc Inc., London, Ontario, Canada; Genesis Software Pty. Ltd, North Adelaide, South Australia, Australia) has also been used to get the information about the abundance of $\mathrm{Na}$. This radar operates at a frequency of $35.25 \mathrm{MHz}$ and provides hourly mean meteor counts, neutral winds, and temperature in the altitude range of 80 to $110 \mathrm{~km}$ with a height resolution of $3 \mathrm{~km}$ (Kumar et al. 2007a). Also, daytime $\mathrm{OH}$ airglow emission intensity at $731.6 \mathrm{~nm}$ wavelength (that originates from about the same altitude region as the $\mathrm{Na}$ airglow) measured using the collocated multi-wavelength dayglow photometer (MWDPM) was used to derive the strength of the gravity waves activity. Details on the MWDPM instrumentation and the dayglow data acquisition/analysis can be found in Sridharan et al. 1998. Further, the concentration of $\left[\mathrm{O}_{3}\right]$ and temperature data obtained from the Microwave Limb Sounder (MLS) instrument onboard the Aura satellite of NASA, USA has also been used (Waters et al. 2006). The pressure data used in this study has been taken from the Sounding of the Atmosphere using Broadband Emission Radiometry (SABER) instrument onboard TIMED satellite (Remsberg et al. 2008). The MLS and SABER data available for the locations nearest to and the $\mathrm{Na}$ abundance information over the region of study have been used for the qualitative evaluation of the VER of the Na airglow. Further, in order to check the variation of solar flux, the F10.7-cm radio flux data, taken from the Space Physics Interactive data resource (http://spidr.ngdc.noaa.gov/spidr/), has also been looked into.

\section{Methodology of investigation}

To study the rationale behind the highly varying nature of the daytime $\mathrm{Na}$ airglow intensity on the three nearconsecutive days of February 2007, the roles of resonance fluorescence and chemistry in the MLT region have been considered. Since the relevant mesospheric fluorescence depends on the available concentration of neutral $\mathrm{Na}$ atom and the prevailing solar radiation, the information on the daytime $\mathrm{Na}$ abundance and solar flux variations on these days have been used to investigate qualitatively the role of fluorescence on the observed intensity variations. Then to investigate the role of chemistry, information on $\mathrm{Na}$ abundance, $\mathrm{O}_{3}$ altitude profiles, and altitude profiles of temperature and pressure have been used to qualitatively appraise the variations of the VER of $\mathrm{Na}$ airglow among these days.

\section{Results and discussions}

Figure 2 shows the temporal variations of daytime $\mathrm{Na}$ airglow intensity measured using the ground based monochromator on 9, 13, and 15 February 2007. It is clear from Figure 2 that compared to that on 13th the maximum intensity levels on 9th and 15th are higher by a factor of approximately 9 and 5, respectively. As already mentioned, the highly varying nature of this airglow intensity might 


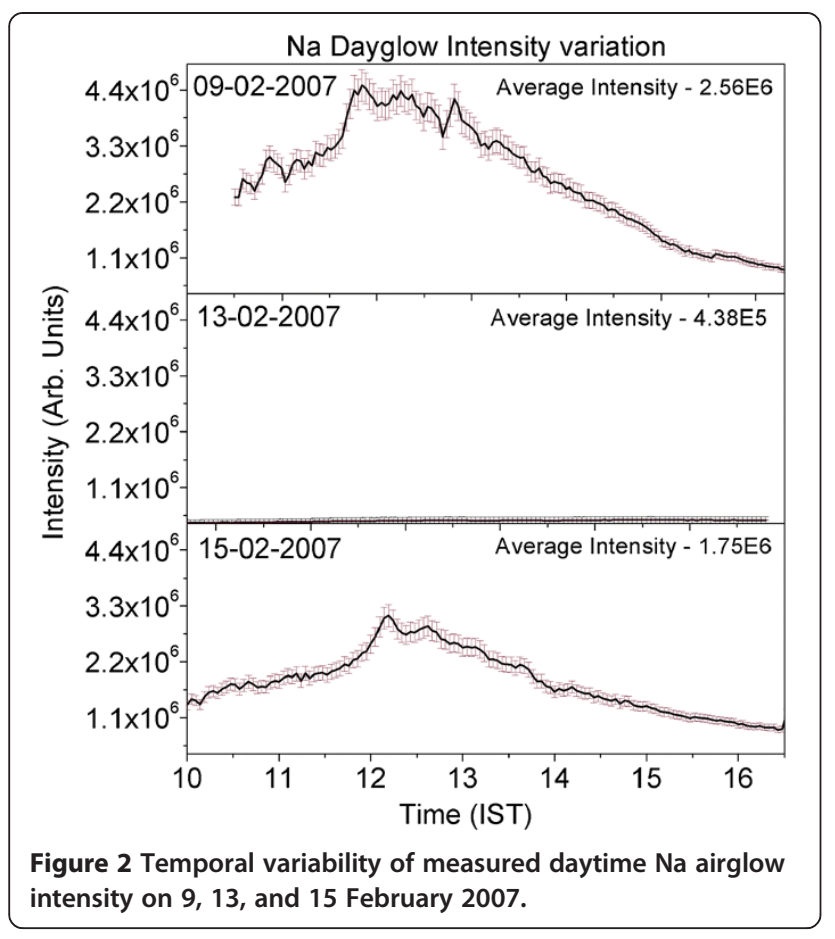

be controlled by resonance fluorescence and the mesosphere chemistry.

To explain the highly varying nature of the observed airglow intensities, let us first consider the role of resonance fluorescence, which can be controlled by concentration of the prevailing neutral $\mathrm{Na}$ atom and the intensity of the solar radiation. To get information on the $\mathrm{Na}$ atom concentrations in those days, we have used the meteor data obtained from the collocated SKiYMET radar. It can be noted in this context that more the meteoric activity, more is the observed $\mathrm{Na}$ abundance as reported by Richter and Sechrist (1979). Figure 3 shows the temporal variations

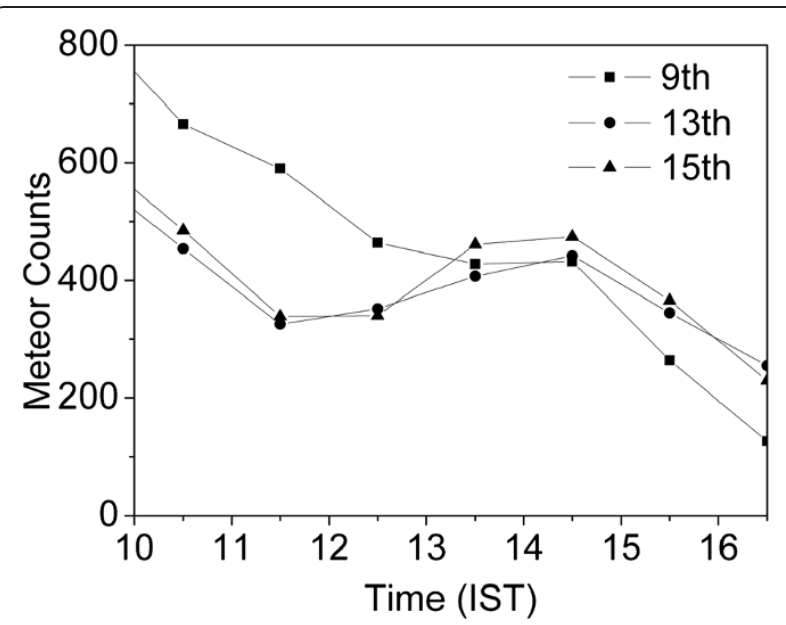

Figure 3 Temporal variations of integrated meteor counts on the 9, 13, and 15 February 2007. of the integrated meteor counts obtained from six different heights between 82 and $98 \mathrm{~km}$ between local times 10:00 to $16: 30 \mathrm{~h}$ on the aforementioned days. The hourly altitude integrated meteor counts on the 9th, 13th, and 15th are respectively 424, 368, and 384, which are in conformity with the trend of the observed intensity variations, with minimum on 13th and maximum on 9th. Consequently, the expected $\mathrm{Na}$ abundance appears to be contributing favorably to the fluorescence, hence to the observed $\mathrm{Na}$ airglow variations on these days. Obviously, five to nine times of airglow intensity differences cannot be accounted for based only on the $\mathrm{Na}$ abundance variations. Here, it can be noticed that the meteor counts are consistent with the airglow intensities during the mentioned 3 days; however, though the time variations of meteor counts on the 3 days are almost similar (Figure 3), the time variation of airglow intensity on 13 February, where the intensity maximum occurred at about local time 16:00, is different from those on the other 2 days, when the intensity maxima happened at about local time 12:00 (Figure 2). Further, it can be noticed from Figure 2 that the average Na dayglow intensity level on the other 2 days are approximately four to six times than that on 13th. In this context, it can be noted that although the sources of neutral $\mathrm{Na}$ atoms are meteors and cosmic dust, day-to-day variation of $\mathrm{Na}$ atoms and, hence, the airglow intensity in the mesospheric altitude might also be controlled by the dynamics. To verify whether the dynamics affected the $\mathrm{Na}$ atom densities on those days significantly, the strength of the gravity waves activity is obtained using the wavelet analysis of the daytime $\mathrm{OH}$ airglow emission intensity measured using the collocated MWDPM. It has been seen that the strength of the gravity waves activity on 13 February was the strongest with almost double than that on the 15th and about four times stronger than that on the 9th (Figure 4). Obviously, it is clear that the inverse of the waves' activity strengths is in compliance with the propensity of the observed intensity variabilities. Hence, it appears that gravity waves activity on the 13th might have a role to influence the $\mathrm{Na}$ atom density. Also, strong waves of $2 \mathrm{~h}$ periodicity between 09:00 to 13:00 and waves of $2.5 \mathrm{~h}$ periodicity from 13:00 onwards to 17:00 are seen on the 13th unlike that on the 9th and 15th. Hence, the role of gravity waves activity on the 13th in leading to the intensity maximum at about $16: 00 \mathrm{~h}$ in contrast to the 12:00 $\mathrm{h}$ intensity maxima on the other 2 days also could not be precluded. On the other hand, the effect of tides has also been investigated. The amplitude of the tidal components has been estimated using the zonal wind data obtained from the collocated SKiYMET radar. The tidal analysis shows that the diurnal, semidiurnal, and terdiurnal tidal activities were almost the same during those days. Hence, though it appears that the dynamics might have played a role in controlling the $\mathrm{Na}$ atom densities on those 


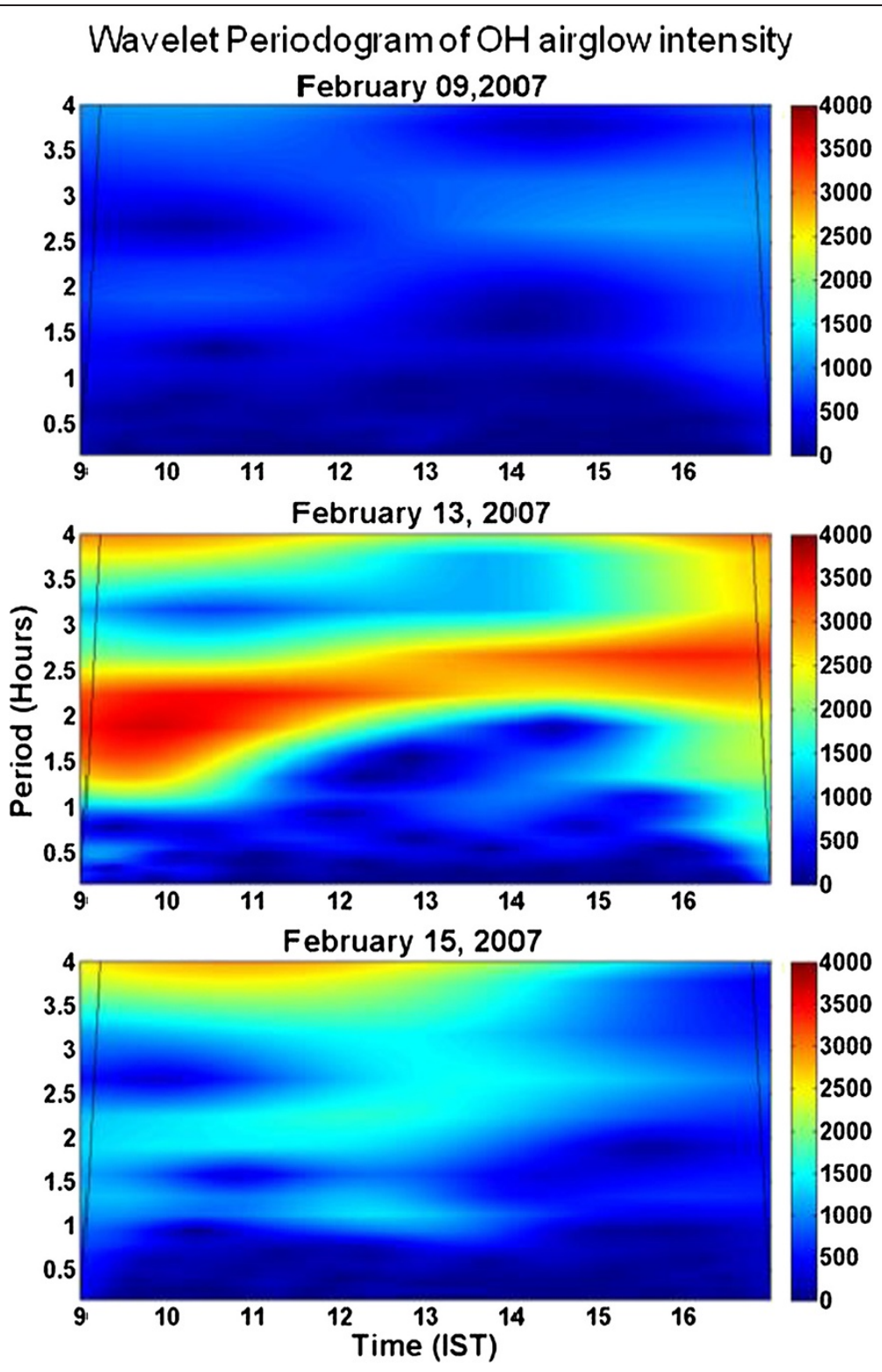

Figure 4 Wavelet periodogram of $731.6 \mathrm{~nm} \mathrm{OH}$ airglow intensity measured using multi-wavelength dayglow photometer.

days, it could not be clearly established. It must be mentioned here that the possibility of transport of sodium atoms due to the processes of advection and winds shear in the MLT region could not also be precluded since this region is dynamically very active. Then, we have considered the F10.7-cm solar radio flux, which represents well the prevailing solar activity levels at the emission height, for exploring the role of solar radiation toward the fluorescence rate variations. Figure 5 shows the daily variation of the F10.7-cm radio flux during the month of February 2007. It is noticed that radio fluxes on the 9th and 15th are respectively 4 units and 1 unit higher than that on 13th, which implies that there occur no significant solar flux variations as such. So the effect of solar activity on the fluorescence rate variations, hence on the observed intensity differences, appears to be insignificant. From the above results, it appears that the resonance fluorescence plays only a minor role, and it alone cannot explain the observed large intensity differences among the mentioned days. Hence, the roles of chemistry behind the substantial intensity variations must be looked into.

To understand the possible role of chemistry on the observed airglow intensity variations among these days, let us consider expression (7) describing the VER of $\mathrm{Na}$ airglow, which can be controlled by the existing [Na], $\left[\mathrm{O}_{3}\right]$ in the emitting layer, and the parameters $k_{1}, \alpha$, and $R_{\mathrm{D}}$. Here, $\mathrm{Na}$ is the airglow-emitting species and its role is looked into first. It has been shown in the preceding 


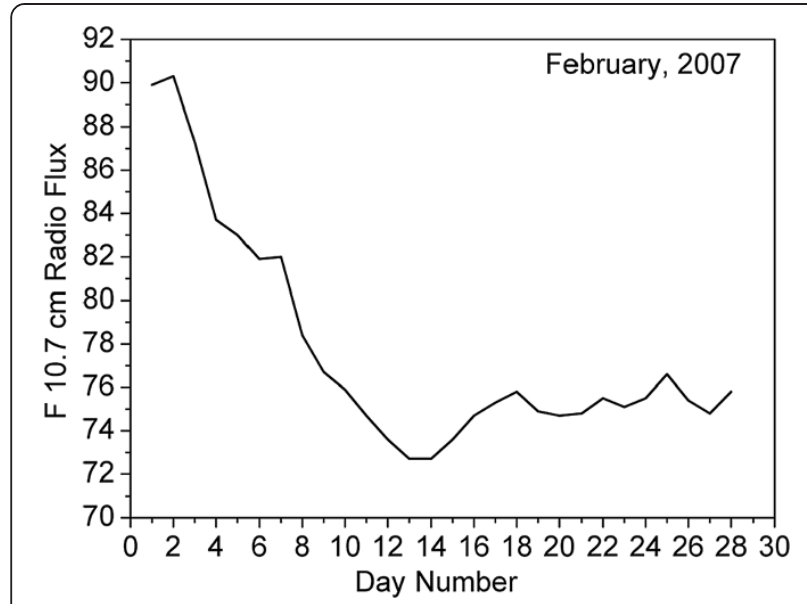

Figure 5 Daily variation of the $\mathrm{F} 10.7-\mathrm{cm}$ radio flux during the month of February 2007.

paragraph that the hourly altitude integrated meteor counts; hence, the expected $\mathrm{Na}$ abundances were more on the 9th and 15th than on the 13th, with maximum on the 9th. Hence, according to expression (7), Na airglow VER is expected to be maximum on the 9th followed by the 15th and 13th in decreasing order, which is corroborated by the $\mathrm{Na}$ airglow intensities on these days as shown in Figure 2. However, the variations in the expected $\mathrm{Na}$ abundances appear to be contributing only to certain extent towards the observed intensity variations on these days. Hence, the role of the other factors must be looked into. For this purpose, we have considered the MLS derived $\left[\mathrm{O}_{3}\right]$ profiles. The snapshot of the $\left[\mathrm{O}_{3}\right]$ profile has been used in this study. Because it is known that over most altitudes in the MLT region during daytime, there occur smaller variations in $\left[\mathrm{O}_{3}\right]$ (Huang et al. 2008). Therefore, it can be assumed that the $\left[\mathrm{O}_{3}\right]$ remains temporally invariant throughout the day, and the snapshot of the $\left[\mathrm{O}_{3}\right]$ profile is the representative of the daytime average. Shown in Figure 6 is the plot of $\left[\mathrm{O}_{3}\right]$ profiles on these days up to approximately $95 \mathrm{~km}$. It is clear from this plot that the average $\left[\mathrm{O}_{3}\right]$ between 80 and $95 \mathrm{~km}$ on these days are of the same order, with average concentration on the 9th is slightly less than that on the 13th and the average concentration on the 15 th is marginally more than that on 13th. Also, at around the peak $\mathrm{Na}$ emission height (approximately $90 \mathrm{~km}),\left[\mathrm{O}_{3}\right]$ on the 9th is marginally more than that on 13th, while $\left[\mathrm{O}_{3}\right]$ on 15 th is about 1.5 times more than on the 13th. Hence, it appears that $\left[\mathrm{O}_{3}\right]$ did not play any role as such towards the observed airglow intensity differences.

Then, we take into account the role of ambient temperature for the observed intensity differences, because it controls the reaction rate coefficient $k_{1}$ of Equation 1 of the Chapman chemical scheme. Depicted in Figure 7 are the altitude profiles of the reaction rate

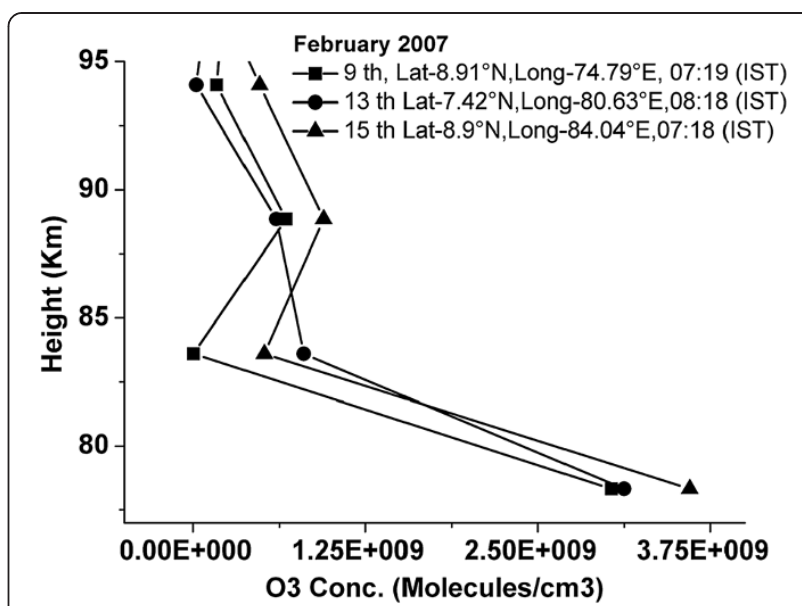

Figure 6 Altitude profile of the MLS-derived $\mathrm{O}_{3}$ concentrations on 9,13 , and 15 February 2007.

coefficients calculated from the MLS-derived temperatures on the concerned days. It is obvious from Figure 7 that the average values of rate coefficients within 80 to $100 \mathrm{~km}$ are almost the same. As Equation 1 determines the rate (Plane 2003) of the $\mathrm{Na}$ airglow emission and there is almost no variation in its rate coefficients among these days, it can be concluded that the ambient temperature did not have any role in the observed intensity differences. The maximum daytime temperature variation in the MLT region over the present location of study as measured using the collocated MWDPM (Sridharan et al. 1998) is approximately $25 \mathrm{~K}$. The change in $k_{1}$ for a temperature change of $25 \mathrm{~K}$ following Equation 5 is negligible and hence does not influence VER appreciably. Therefore, it can be assumed that the rate coefficient profiles calculated from the MLS-derived temperatures in the MLT region are temporally invariant throughout the day

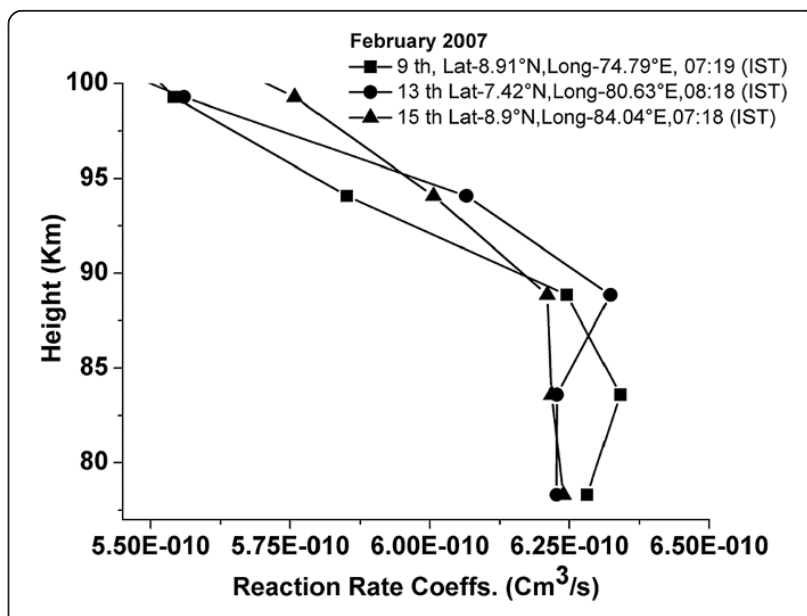

Figure 7 Altitude profiles of the reaction rate coefficients on 9, 13, and 15 February 2007. 
and hence, the snapshot of the calculated rate coefficient profile can represent its daytime average.

Hence, from the analyses of the roles of resonance fluorescence and chemistry in the preceding paragraphs and following Equation 7, it seems that the other factors that could be crucial for the observed intensity variations on the mentioned days are $\alpha$ and $R_{\mathrm{D}}$. In this context, it can be noted that Sarkhel et al. (2009) have suggested the variations of the parameters $\alpha$ and $R_{\mathrm{D}}$ due to collisional quenching of $\mathrm{NaO}^{\prime \prime}(\mathrm{A})$ with the ambient gas lead to the observed day-to-day differences in the $\mathrm{Na}$ airglow. Now, it is known that quenching of $\mathrm{NaO}^{\prime \prime}(\mathrm{A})$ with the ambient gas can be influenced by pressure variations in the emitting altitude region. Hence, we next consider the variations of $\alpha$ and $R_{\mathrm{D}}$ due to pressure variations to account for the observed airglow intensity variability on the mentioned days. Figure 8 shows the available height profiles of the pressures obtained from SABER instrument on these days. It is obvious from this plot that the pressure levels on the 9th and 15th is significantly less than that on the 13th throughout the 85 to $95 \mathrm{~km}$, i.e., the key-emitting altitude range. In this context, it can be noted that the average day-to-day pressure variabilities at approximately $90 \mathrm{~km}$ altitude over the present region of study is extremely small, $0.00005 \mathrm{hPa}$ /day (Kumar 2007b). To understand the observed pressure variations, the ongoing changes in the energetics and dynamics of the upper mesospheric region have been analyzed. It is observed from the SKiYMET radar data that on 13th, the mesopause temperature was $11 \mathrm{~K}$ more than those on the 9th and 15th. Also, as mentioned earlier, gravity waves activity on 13 February was strongest with almost double than that on the 15th and about four times stronger than that on 9th. On the other hand, it has already been seen that the diurnal, semidiurnal, and terdiurnal tidal activities were almost the same during

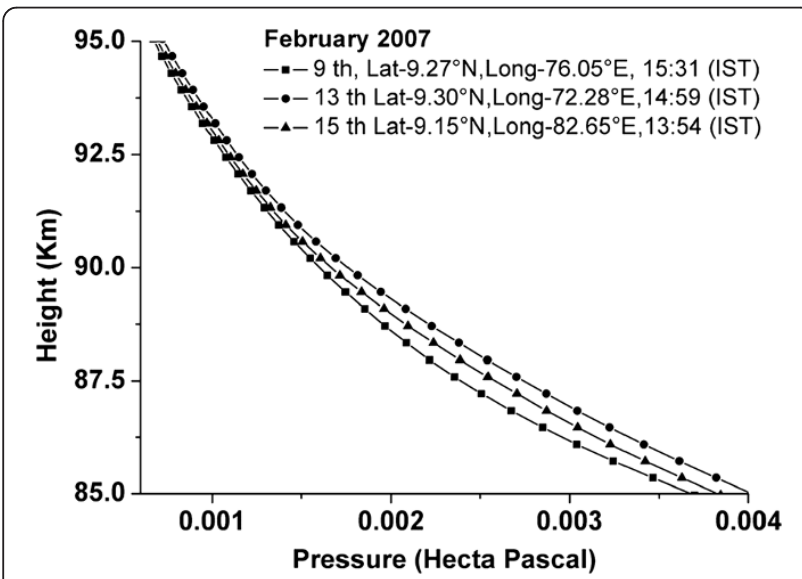

Figure 8 Altitude profiles of pressures obtained from SABER instrument on 9, 13, and 15 February 2007. those days. Hence, it is conjectured that the combination of the changes in energetics and dynamics of the MLT region due to temperature change and dynamics has led to higher pressure on 13th. Now, more the pressureenhanced is the quenching of $\mathrm{NaO}^{\prime \prime}(\mathrm{A})$ to $\mathrm{NaO}(\mathrm{X})$ leading to less abundance of $\mathrm{NaO}^{\prime \prime}(\mathrm{A})$. It has been shown by Herschbach et al. (1992) and Joo et al. (1999) that less is the abundance of $\mathrm{NaO}^{\prime \prime}(\mathrm{A})$, smaller will be the value of $\alpha$. Also, based on theoretical analysis, Herschbach et al. (1992) showed that $\alpha$ would be on the higher side (approximately 0.67 ), if $\mathrm{NaO}^{\prime \prime}(\mathrm{A})$ reacts entirely with $\mathrm{O}$ before being quenched to $\mathrm{NaO}(\mathrm{X})$. This finding was also supported by Griffin et al. (2001). Also, though the clear evidence on the variation of $R_{\mathrm{D}}$ with the quenching process is not available in the literature, Slanger et al. (2005) has postulated that the value of $R_{\mathrm{D}}$ will be on the lower side (approximately 1.3) if the abundance of $\mathrm{NaO}^{\text {" }}$ (A) is less, whereas $R_{\mathrm{D}}$ will be on the higher side (approximately 2.4) if $\mathrm{NaO}^{\prime \prime}(\mathrm{A})$ abundance is more. Therefore, it appears that on the 13th, because of more ambient pressure, quenching of $\mathrm{NaO}^{\prime \prime}(\mathrm{A})$ was more, hence both the values of $\alpha$ and $R_{\mathrm{D}}$ were on the lower side. Lower values of both $\alpha$ and $R_{\mathrm{D}}$ make the factor $\left(1+R_{\mathrm{D}}\right)^{-1} \alpha$ of Equation 7 smaller and this might have led to smaller VER of Equation 7, and hence less airglow intensity on the 13th. In other words, it appears that on the 9th and 15th, because of less ambient pressures, and hence reduced quenching, both the values of $\alpha$ and $R_{\mathrm{D}}$ were on the higher side, thereby making the enhanced airglow intensity on these days compared to that on 13th. It is seen from Equation 7 that the ratio of $\left(1+R_{\mathrm{D}}\right)^{-1} \alpha$ for larger values of $\alpha$ and $R_{\mathrm{D}}$ to that for smaller sets of values can significantly change the VER ratio, hence the airglow intensity ratio keeping $k_{1},[\mathrm{Na}]$, and $\left[\mathrm{O}_{3}\right]$ unchanged. It is also obvious from Equation 7 that as the pressure throughout the emitting region decreases from the 13th to 15th and then to the 9th, the observed airglow intensity increases in the same order of days. Thus, it appears that collisional quenching differences because of significant pressures variations are believed to be contributing considerably for the substantial intensity variations among these days.

However, since the direct quantitative measurements of mesospheric $\mathrm{Na}$ concentration were not available over or nearest to the region of study and also the quantitative detailed data on the dependence of $\alpha$ and $R_{\mathrm{D}}$ on pressure were not available in the literature, contributions of $\mathrm{Na}$ abundance and the pressure-dependent collisional quenching towards the resonance fluorescence/ chemistry could not be quantitatively established. Nonetheless, taking into considerations of all the possible factors, it emerges that whereas resonance fluorescence, through only the $\mathrm{Na}$ abundance variations, plays only a minor role, the chemistry through the $\mathrm{Na}$ abundance 
variations and the variations in the collisional quenching of $\mathrm{NaO}$ (A) due to significant pressure differences, has contributed to greater extent towards the observed significant intensity differences among these days. This work supports the observations made by Sarkhel et al. (2009) and reaffirms the role of collisional quenching towards controlling the $\mathrm{Na}$ airglow intensity variations.

In the present work, in the absence of direct $\mathrm{Na}$ atom density measurement, meteor data has been used as the indicator of the $\mathrm{Na}$ abundances, and it is seen that the meteor counts are consistent with the airglow intensities during the mentioned 3 days. It is known that although the sources of neutral $\mathrm{Na}$ atoms are meteors and cosmic dust, the day-to-day variation of $\mathrm{Na}$ atoms in the mesosphere is mostly controlled by the dynamics (tides and gravity waves). Hence, as per the results of the present work, it seems that dynamics did not cause the day-to-day variation of $\mathrm{Na}$ density significantly on those days. However, using the wavelet analysis and the tidal analysis, as shown early in the results, it seems that the dynamics might have played a role in controlling the day-to-day $\mathrm{Na}$ density variation on those days, but its role could not be clearly established.

\section{Conclusions}

A ground-based 1-m scanning monochromator has been used to measure the significant variations in daytime sodium $\mathrm{D}_{1}$ airglow intensity $(589.6 \mathrm{~nm})$ from Trivandrum $\left(8.5^{\circ} \mathrm{N}, 77^{\circ} \mathrm{E}\right)$, a near-equatorial station in India during the three near-consecutive days of February 2007. The possible reasons for the significant intensity differences have been investigated through considerations of the roles of both the resonance fluorescence and the mesospheric chemistry. From deliberations of all the possible factors, it appears that whereas resonance fluorescence, through only the $\mathrm{Na}$ abundance variations, plays only a minor role, its the chemistry, through the $\mathrm{Na}$ abundance variations and the variations in the collisional quenching of excited $\mathrm{NaO}$ (A) due to significant pressure differences, that has played greater role towards the observed significant intensity differences among these days. However, since the direct quantitative measurements of mesospheric Na concentration were not available and also the quantitative detailed data on the dependence of $\alpha$ and $R_{\mathrm{D}}$ on pressure were not available in the literature, contributions of resonance fluorescence and chemistry could not be quantitatively established. This work supports the inference made by Sarkhel et al. (2009) that the collisional quenching controls the $\mathrm{Na}$ airglow intensity variability through the variations of $\alpha$ and $R_{\mathrm{D}}$.

\section{Competing interests}

The authors declare that they have no competing interests.

\section{Authors' contributions}

MMH conceived and designed the present study, performed the experiment for the day time Na airglow emission measurement in addition to collection of other associated data, carried out the data analysis, drafted the manuscript, and coordinated the study. CV was involved in the data collection, data analysis, and some necessary discussions. SSG participated in conducting the experiment as well as in manuscript preparation. TKP participated in designing the study, data analysis, as well as in the useful discussions concerning the study. All authors read and approved the final manuscript.

Received: 13 June 2013 Accepted: 23 March 2014

Published: 16 June 2014

\section{References}

Bernard R (1939) The identification and the origin of atmospheric sodium. Astrophys J 89:133-135

Blamont JE, Donahue TM (1961) The dayglow of the sodium D lines. J Geophys Res 66:1407-1427

Chapman S (1939) Notes on atmospheric sodium. J Astrophys 90:309-316

Clemesha BR, Simonich DM, Takahashi H, Melo SML, Plane JMC (1995) Experimental evidence for photochemical control of the atmospheric sodium layer. J Geophys Res 100(D9):18909-18916

Fan ZY, Plane JMC, Gumbel J, Stegman J, Llewellyn EJ (2007) Satellite measurements of the global mesospheric sodium layer. Atmos Chem Phys 7:4107-4115

Gibson AJ, Sandford MC (1972) Daytime laser radar measurements of atmospheric sodium layer. Nature 239:509-511

Griffin J, Worsnop DR, Brown RC, Kolb CE, Herschbach DR (2001) Chemical kinetics of the $\mathrm{NaO}\left(\mathrm{A}^{2} \Sigma^{+}\right)+\mathrm{O}\left({ }^{3} \mathrm{P}\right)$ reaction. J Phys Chem A 105:1643-1648

Harrell SD, She CY, Yuan T, Krueger DA, Plane JMC, Slanger T (2010) The Faraday filter-based spectrometer for observing sodium nightglow and studying atomic and molecular oxygen associated with the sodium chemistry in the mesopause region. J Atmos Sol Terr Phys 72:1260-1269, ISSN 1364-6826

Hecht JH, Collins S, Kruschwitz C, Kelley MC, Roble RG, Walterscheid RL (2000) The excitation of the Na airglow from Coqui Dos rocket and ground-based observations. Geophys Res Lett 27(4):453-456

Herschbach DR, Kolb CE, Worsnop DR, Shi X (1992) Excitation mechanism of the mesospheric sodium nightglow. Nature 56:414-416

Hossain MM, Pant TK, Vineeth C, Sumod SG, Sridharan R (2010) Daytime sodium airglow emission measurements over Trivandrum using a scanning monochromator: first results. Ann Geophys 28:2071-2077

Huang FT, Mayr HG, Russell JM III, Mlynczak MG, Reber CA (2008) Ozone diurnal variations and mean profiles in the mesosphere, lower thermosphere, and stratosphere, based on measurements from SABER on TIMED. J Geophys Res 113, A04307

Joo S, Worsnop DR, Kolb CE, Kim SK, Herschbach DR (1999) Observation of the A ${ }^{2} \Sigma^{+} \leftarrow X^{2} \Pi$ electronic transition of NaO. J Phys Chem A 103:3193-3199

Kirchhoff V, Clemesha BR (1983) The atmospheric neutral sodium layer, 2. Diurnal variations. J Geophys Res 88:442-450

Kumar KK (2007b) Temperature profiles in the MLT region using radar-meteor trail decay times: comparison with TIMED/SABER observations. Geophys Res Lett 34:L16811

Kumar YB, Prasanth PV, Rao DN, Murthy MS, Krishnaiah M (2007a) The first lidar observations of the nighttime sodium layer at low latitudes Gadanki $\left(13.5^{\circ} \mathrm{N}\right.$, $79.2^{\circ}$ E), India. Earth Planets Space 59:601-611

Kumar KK, Ramkumar G, Shelbi ST (2007a) Initial results from SKiYMET meteor radar at Thumba $3(8.5 \mathrm{~N}, 77 \mathrm{E})$ : 1. Comparison of wind measurements with MF spaced antenna radar system. Radio Sci 42

Plane JMC (2003) Atmospheric chemistry of meteoric metals. Chem Rev 103:4963-4984

Plane JMC, Husain D (1986) Determination of the absolute rate constant for the reaction $\mathrm{O}+\mathrm{NaO}-\mathrm{Na}+\mathrm{O}_{2}$ by time-resolved atomic chemiluminescence at $\lambda-589 \mathrm{~nm}\left(\mathrm{Na}\left(3^{2} \mathrm{P}_{\mathrm{J}}\right) \mathrm{Na}\left(3^{2} \mathrm{~S}_{1 / 2}\right)+\mathrm{hv}\right)$. J Chem Soc Faraday Trans II82:2047-2052

Plane JMC, Saiz-Lopez A, Allan BJ, Ashworth SA, Jenniskens P (2007) Variability of the mesospheric nightglow during the 2002 Leonid storms. Adv Space Res 39:562-566

Plane JMC, Oetjen H, de Miranda M, Saiz-Lopez A, Gausa M, Williams B (2012) On the sodium $D$ line emission in the terrestrial nightglow. J Atmos Sol Terr Phys 74:181-188 
Remsberg EE, Marshall BT, Garcia-Comas M, Krueger D, Lingenfelser GS, Martin-Torres J, Mlynczak MG, Russell JM, Smith AK, Zhao Y, Brown C, Gordley LL, Lopez-Gonzalez MJ, Lopez-Puertas M, She C-Y, Taylor MJ, Thompson RE (2008) Assessment of the quality of the Version 1.07 temperature-versuspressure profiles of the middle atmosphere from TIMED/SABER. J Geophys Res-Atmospheres 113:D17101

Richter ES, Sechrist CF Jr (1979) A meteor ablation-cluster ion atmospheric sodium theory. Geophys Res Lett 6(3):183-186

Sarkhel S, Sekar R, Chakrabarty D, Narayanan R, Sridharan S (2009) Simultaneous sodium airglow and lidar measurements over India: a case study. I Geophys Res 114, A10317

She CY, Chen SS, Hu ZL, Sherman J, Vance JD, Vasoli V, White MA, Yu J, Krueger DA (2000) Eight-year climatology of nocturnal temperature and sodium density in the mesopause region (80 to $105 \mathrm{~km})$ over Fort Collins, $\mathrm{CO}\left(41^{\circ} \mathrm{N}, 105^{\circ} \mathrm{W}\right)$. Geophys Res Lett 27:3289-3292

Shi X, Herschbach DR, Worsnop DR, Kolb CE (1993) Molecular-beam chemistry - magnetic deflection analysis of monoxide electronic states from alkali-metal atom plus ozone reactions. J Phys Chem 97:2113-2122

Sipler DP, Biondi MA (1978) Interferometric studies of the twilight and night-glow sodium D-line profiles. Planet Space Sci 26:65-73

Slanger TG, Cosby PC, Huestis DL, Saiz-Lopez A, Murray BJ, O'Sullivan DA, Plane JMC, Prieto CA, Martin-Torres FJ, Jenniskens P (2005) Variability of the mesospheric nightglow sodium D2/D1 ratio. J Geophys Res 110, D23302

Slanger TG, Cosby PC, Huestis DL, Sharpee BD (2006) Review of tropical nightglow studies with astronomical instruments. J Atmos Sol-Terres Phys 68:1426-1440

Slipher VM (1929) Emissions in the spectrum of the light of the night sky. Publ Astron Soc Pacific 41:262-265

Sridharan R, Modi NK, Raju DP, Narayanan R, Pant TK, Taori A, Chakrabarty D (1998) Multiwavelength daytime photometer-a new tool for the investigation of atmospheric processes. Meas Sci Technol 9:585-591

Waters JW, Froidevaux L, Harwood RS, Jarnot RF, Pickett HM, Read WG, Siegel PH, Cofield RE, Filipiak MJ, Flower DA, Holden JR, Lau GK, Livesey NJ, Manney GL, Pumphrey HC, Santee ML, Wu DL, Cuddy DT, Lay RR, Loo MS, Perun VS, Schwartz MJ, Stek PC, Thurstans RP, Boyles MA, Chandra KM, Chavez MC, Chen G-S, Chudasama BV, Dodge R (2006) The Earth observing system microwave limb sounder (EOS MLS) on the Aura satellite. IEEE Trans Geosci Remote Sens 44(5):1075-1092

Wright TG, Ellis AM, Dyke JM (1993) A study of the products of the gas-phase reaction $\mathrm{M}+\mathrm{N}_{2} \mathrm{O}$ and $\mathrm{M}+\mathrm{O}_{3}$, with ultraviolet photoelectron spectroscopy. J. Chem Phys 98:2891-2907

Zahn UV, Hansen G, Kurzawa H (1988) Observations of the sodium layer at high latitudes in summer. Nature 331:594-596

\section{doi:10.1186/1880-5981-66-56}

Cite this article as: Hossain et al:: Highly varying daytime sodium airglow emissions over an equatorial station: a case study based on the measurements using a grating monochromator. Earth, Planets and Space 2014 66:56.

\section{Submit your manuscript to a SpringerOpen ${ }^{\circ}$ journal and benefit from:}

- Convenient online submission

- Rigorous peer review

- Immediate publication on acceptance

- Open access: articles freely available online

- High visibility within the field

- Retaining the copyright to your article

Submit your next manuscript at $\gg$ springeropen.com 